\title{
MODIFIED DEGA OSTEOTOMY IN TREATING DEVELOPMENTAL DYSPLASIA OF THE HIP
}

\section{OSTEOTOMIA DE DEGA MODIFICADA NO TRATAMENTO DA DISPLASIA DO DESENVOLVIMENTO DO QUADRIL}

\author{
Roberto Guarniero ${ }^{1}$, Fernando Barbosa Sanchez ${ }^{1}$, Bruno Sergio Ferreira Massa ${ }^{1}$, Nel Botter Montenegro ${ }^{1}$, \\ Patrícia Moreno Grangeiro ${ }^{1}$, Luiz Renato Agrizzi De Angeli ${ }^{1}$
}

1. Pediatric Orthopedics Group, Instituto de Ortopedia e Traumatologia, Hospital das Clínicas HCFMUSP, Faculdade de Medicina, Universidade de São Paulo, São Paulo, SP, Brazil.

\begin{abstract}
Objective: To retrospectively evaluate the preliminary postoperative results of modified Dega-type acetabular osteotomy to treat developmental dysplasia of the hip, confirming the efficacy and reproducibility of this technique. Methods: This retrospective study included patients older than 18 months. A total of 19 hips underwent modified Dega osteotomy. Results: Satisfactory results were obtained, with an average decrease of the acetabular index from 39.2 to 20.6 degrees. The final average center edge angle was 29.6 degrees. Hip joint congruence was reestablished in all cases, and as of this writing, only one case developed necrosis in the femoral head during follow-up. Conclusion: Modified Dega osteotomy demonstrated good initial results, as well as the potential for use in treating developmental dysplasia of the hip. Level of Evidence IV; Case series.
\end{abstract}

Keywords: Arthroplasty, replacement, hip/methods. Hip dislocation, congenital. Osteotomy. Radiography.

\section{RESUMO}

Objetivo: Avaliar, retrospectivamente, os resultados preliminares do pós-operatório de pacientes com displasia do desenvolvimento do quadril, tratados com osteotomia acetabular do tipo Dega modificada e, dessa forma, confirmar a eficácia da técnica. Métodos: Neste estudo retrospectivo foram incluídos pacientes com idades acima de 18 meses. No total, 19 quadris foram submetidos à osteotomia de Dega modificada. Resultados: Os resultados foram satisfatórios, com diminuição média do índice acetabular de 39,2 para 20,6 graus. A média final do ângulo centro-borda foi de 29,6 graus. Em todos os casos houve restabelecimento da congruência articular dos quadris e, até o momento, um caso apresentou necrose da cabeça do fêmur no mesmo período do seguimento. Conclusão: A osteotomia de Dega modificada demonstrou bons resultados iniciais e potencial para ser empregada no tratamento da displasia do desenvolvimento do quadril. Nível de Evidência IV; Série de casos.

Descritores: Artroplastia de quadril/métodos. Luxação congênita de quadril. Osteotomia. Radiografia.

Citation: Guarnieiro R, Sanchez FB, Massa BSF, Montenegro NB, Grangeiro PM, De Angeli LRA. Modified dega osteotomy in treating developmental dysplasia of the hip. Acta Ortop Bras. [online]. 2018;26(1):30-2. Available from URL: http://www.scielo.br/aob.

\section{INTRODUCTION}

Developmental dysplasia of the hip $(\mathrm{DDH})$ describes a broad spectrum of pathological conditions ranging from subtle acetabular dysplasia to irreducible hip dislocation. Salter, ${ }^{1}$ and later Wedge, ${ }^{2}$ showed that acetabular dysplasia was secondary to malpositioning of the hip. This condition generates marginal erosion from torsion, localized hypoplasia, or overall deficiency of the acetabulum, and reduces the contact area between the acetabular surface with a frequently misshapen femoral head.

The incidence of DDH varies depending on several factors, including even geography. Approximately one in every 1,000 newborn infants is born with hip dislocation and around 10 in 1,000 with hip subIuxation. ${ }^{3}$ In Brazil, Volpon and Carvalho Filho ${ }^{4}$ found an incidence of 2.31 per 1,000 . The disease is more prevalent in children born breech and girls; the left side is most affected, firstborn children are twice as likely to be affected than subsequent siblings, and positive family history may be involved in $12 \%$ to $33 \%$ of cases. ${ }^{5}$ The goal of treatment in older children is to delay or prevent the development of osteoarthritis and avoid the need for arthroplasty at a young age. ${ }^{2}$

Several pelvic osteotomies have been described to treat residual acetabular dysplasia secondary to DDH. These osteotomies can be performed as an isolated procedure or in conjunction with open reduction of the hip and proximal femoral osteotomy.

In 1969, Dega ${ }^{6}$ reported what he described as a transiliac osteotomy, which consists of an incomplete supra-acetabular osteotomy that preserves the internal plate of the posterior pelvis in relation to the iliopectinial line, preserving the entire cortex of the sciatic notch

All authors declare no potential conflict of interest related to this article.

Work conducted at the Department of Pediatric Orthopedics, Instituto de Ortopedia e Traumatologia, Hospital das Clínicas HCFMUSP, Faculdade de Medicina, Universidade de São Paulo, São Paulo, SP, Brazil.

Correspondence: Fernando Barbosa Sanchez. Rua Oscar Freire 2040, Apto 153, Pinheiros, São Paulo, SP, Brazil. 05409-011. sanchezfbs@gmail.com 
and leaving a posteromedial hinge intact. A graft of iliac bone is placed in the osteotomy. This surgical technique has been shown to be capable of improving lateral coverage of the hip to near-normal values in patients with DDH. In 1992, Mubarak et al. ${ }^{7}$ described the modified Dega technique to treat hip dislocation in patients diagnosed with spastic cerebral palsy.

Although there is significant causality for the Salter osteotomy to correct hip dysplasia in patients with $\mathrm{DDH}$ as well as for the use of the Dega osteotomy to treat hip dysplasia in patients with cerebral palsy, there are few publications in Portuguese on the use of the Dega technique in patients diagnosed with $\mathrm{DDH}$.

The objective of this study is to retrospectively assess the preliminary postoperative results in patients with developmental dysplasia of the hip who were treated with modified Dega-type acetabular osteotomy, thus confirming the validity and reproducibility of this technique in treating DDH. The target in the follow-up was new radiographic analysis at five and 10 years after the procedure.

\section{METHODS}

This study was approved by the institutional review board at the Instituto de Ortopedia e Traumatologia do Hospital das Clínicas de São Paulo, where the study was conducted (approval number 14117, process number 1,433,929). Since this is a retrospective case series using X-rays, informed consent was not required from patients.

\section{Inclusion criteria}

We included patients over age 18 months with a diagnosis of DDH who underwent modified Dega osteotomy between January 2012 and May 2016 at the Institute of Orthopedics and Traumatology, at HCFMUSP. Exclusion criteria were patients with diagnoses of genetic syndromes and/or neuromuscular alterations.

All procedures were conducted by the same group of surgeons specialized in pediatric orthopedics, and followed the technique described by Mubarack et al. ${ }^{7}$

The femur was shortened when necessary to facilitate reduction of the hip, and the principle of relative stability was used along with a $3.5 \mathrm{~mm}$ DCP plate with four holes. This shortening does not correct rotation and varusing.

We analyzed anteroposterior X-rays of the pelvis taken before the procedure and in the early and late post-procedure periods. The X-rays were analyzed by an experienced pediatric orthopedist from our institute who was familiar with the parameters evaluated, but blinded with regard to the images and the study. The images were randomly distributed before the evaluation. The parameters evaluated in all the X-rays were acetabular index, center-edge angle, Shenton line, and presence of avascular necrosis of the femoral head in accordance with the criteria by Salter. ${ }^{8-10}$ (Figures 1 and 2)

\section{Statistical analysis}

The values for acetabular index, center edge angle, and measurement of the Shenton line before surgery, immediately after the surgery, and one in the late postoperative period were compared using a paired t-test.

\section{RESULTS}

The sample consisted of 17 patients (19 hips) with a minimum age of 2 years and 1 month ( $2 \mathrm{y} 1 \mathrm{~m})$ and a maximum age of $7 \mathrm{y} 2 \mathrm{~m}$, mean age of $3 y 6 \mathrm{~m}$; 3 patients (15.79\%) were male and 16 were female (84.21\%). The right side was affected in 9 hips (47.4\%) and the left in 10 hips (52.6\%). Two patients were bilaterally affected. Shortening of the femur was associated in 6 cases (31.6\%) to facilitate hip reduction. (Table 1) Mean follow-up time was 18.2 months.

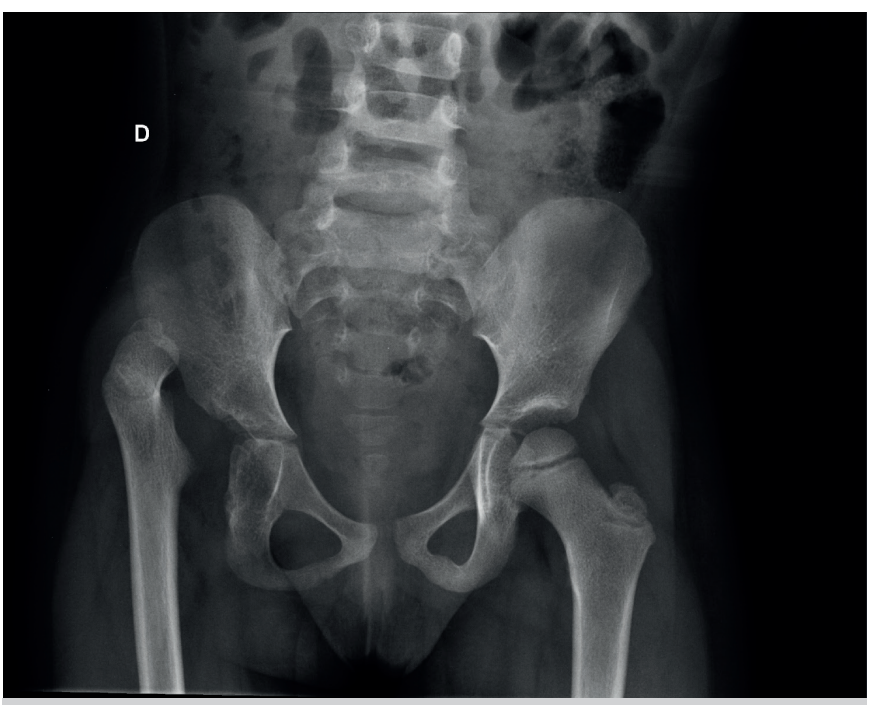

Figure 1. Preoperative antero-posterior $\mathrm{X}$-ray of the pelvis from one of the patients evaluated in the study. Source: Instituto de Ortopedia e Traumatologia, Hospital das Clínicas, Faculdade de Medicina, Universidade de São Paulo.

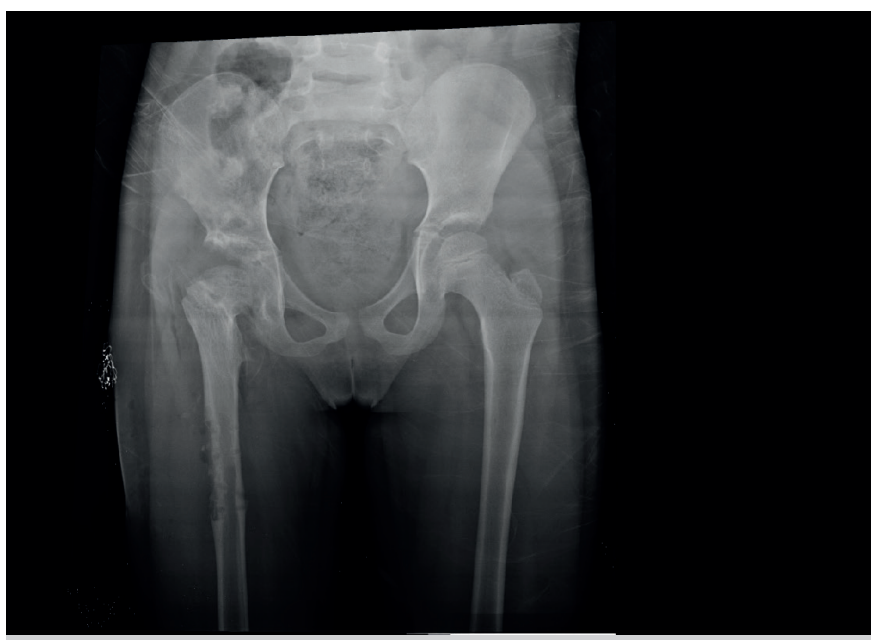

Figure 2. Late postoperative $\mathrm{X}$-ray of the pelvis from the same patient in Figure 1. Source: Instituto de Ortopedia e Traumatologia, Hospital das Clínicas, Faculdade de Medicina, Universidade de São Paulo.

\begin{tabular}{c|c} 
Table 1. Patient characteristics. \\
\hline Variable & Description (N=19) \\
\hline Age (months), mean \pm SD & $42.8 \pm 13.9$ \\
\hline Sex, $n(\%)$ & \\
\hline Female & $16(84.2 \%)$ \\
\hline Male & $3(15.8 \%)$ \\
\hline Side, $n(\%)$ & \\
\hline Right & $9(47.4 \%)$ \\
\hline Left & $10(52.6 \%)$ \\
\hline
\end{tabular}

One patient developed avascular necrosis during the follow-up period. Postoperative complications such as infection, wound dehiscence, and redislocation were not observed.

The mean preoperative acetabular index was 39.26 degrees, ranging from 21 to 52 degrees, and decreased to a mean value of 24.32 degrees in the immediate postoperative period, ranging from 12 to 32 degrees; at the end of the study period, this mean value 
was 20.68 degrees, ranging from 14 to 29 degrees. A significant difference was seen between the mean acetabular index prior to the surgery and in the immediate postoperative period $(p<0.01)$, and this was seen in comparing the preoperative and late follow-up values $(p<0.01)$. A significant difference was seen between the mean acetabular index and the values immediately after the surgery and at the end of the study $(p<0.01)$. (Figure 3 )

The center-edge angle in the preoperative period was not included in the analysis, because the hips were dislocated, which impairs its calculation. In the immediate postoperative period the average center-edge angle was 25.95 degrees, ranging from 15 to 35 degrees, and at late follow-up the mean center-edge angle was 29.63, ranging from 17 to 50 degrees $(p<0.085)$. This difference, although not statistically significant, suggests some degree of remodeling and improvement of acetabular coverage over time.

With regard to the Shenton line, this was restored in $100 \%$ of patients at late follow-up.

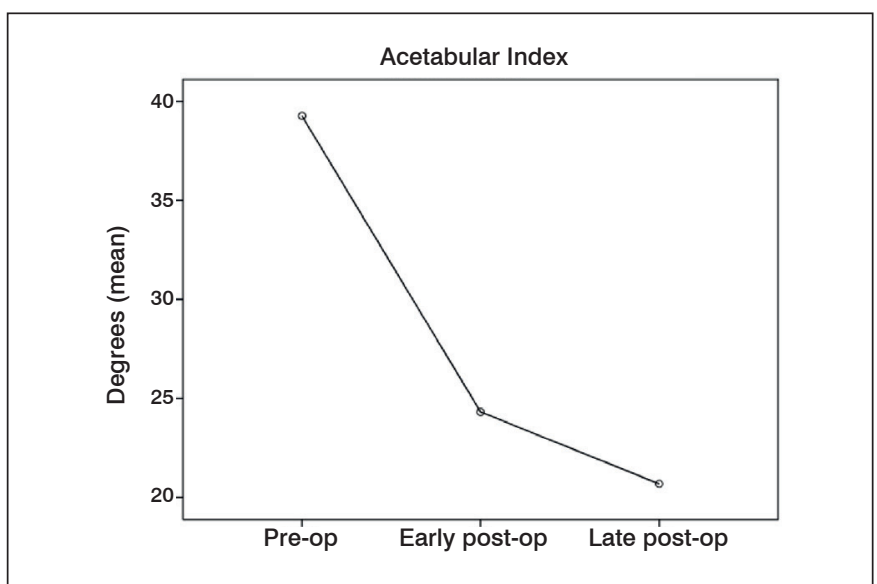

Figure 3. Preoperative, early postoperative, and late postoperative outcomes for the acetabular index.

\section{DISCUSSION}

Treatment of late-diagnosed DDH still represents a major challenge for pediatric orthopedic surgeons. Although several pelvic osteotomy techniques have been developed to restore hip joint congruence in these children, there is still debate about which technique is best. The Dega osteotomy, modified by Mubarak et al. ${ }^{7}$ in 1992 , became the surgical procedure of choice to treat children with neuromuscular dysplasia. Few studies have correlated this type of osteotomy with treatment of DDH.

This surgical technique was seen to successfully restore hip joint congruence from the radiographic parameters studied. The acetabular index decreased by an average of 39.2 to 20.6 degrees, results comparable to those found in previous studies, such as by Ahmed Al-Ghamdi et al., ${ }^{11}$ who found a decrease in the acetabular index from 37 to 19 in a series of 21 cases.

The mean late postoperative center edge angle was 29.63, within the range of 25 and 40 considered normal. ${ }^{12}$ According to Wiberg ${ }^{8}$ and Cooperman et al., ${ }^{13}$ center edge angle values below 10 are closely linked to the development of osteoarthritis in adults. The difference between the values of the center edge angle in the immediate postoperative and late postoperative periods was not initially statistically significant. In this present study, one of the patients developed necrosis of the femoral head. In all of the patients, hip reduction was obtained and the Shenton line was restored. Despite the satisfactory results, some limitations of this study should be highlighted. One limitation is the immaturity of the hip in childhood and the fact that changes related to dysplasia make the measurements mentioned above difficult to obtain. Parameters such as the lateral edge of the acetabulum, the core of ossification of the femoral head, and triradiate cartilage, if altered, can complicate measurement of the indices. Another limitation is the lack of correlation between the clinical and radiographic data, for example range of motion, claudication, and leg length discrepancy.

Despite the limitations presented, the radiographic data from our study showed very satisfactory results which closely resembled previous studies. ${ }^{11,14}$ The restoration of joint congruence is the final goal in treating children with $\mathrm{DDH}$, and through this case series we show that the modified Dega osteotomy can be used for this purpose. In the present study, there was no increase in the number of early complications. Other techniques should be compared in the near future, but we believe that the selection of techniques should consider not only radiographic and clinical data, but also the experience of each surgeon.

\section{CONCLUSION}

Modified Dega osteotomy showed good initial radiological results and the potential for use in treating developmental dysplasia of the hip.

AUTHORS' CONTRIBUTIONS: Each author made significant individual contributions to this manuscript. RG $(0000.0002 .1798 .0653)^{\star}$, LRAA $(0000.0003 .3779 .6914)^{\star}$, NBM $(0000.0002 .0705 .1623)^{*}$ and PMG $(0000.0002 .1533 .659 X)^{*}$ contributed to the intellectual content and analyzed the results. FBS $(0000.0003 .2211 .9347)^{*}$ drafted the article, performed the statistical analysis, revised the article and submitted the manuscript. BSFM (0000.0002.3335.8661)* contributed to the intellectual content, analyzed the results, revised the manuscript, and performed the surgeries. *ORCID (Open Researcher and Contributor ID).

\section{REFERENCES}

1. Salter RB. Role of innominate osteotomy in the treatment of congenital dislocation and subluxation of the hip in the older child. J Bone Joint Surg Am. 1966;48(7):1413-39.

2. Wedge JH. Hip joint acetabular dysplasia. J Pediatr Orthop. 1997;17(2):141-2.

3. Guarniero R. Displasia do desenvolvimento do quadril: atualização. Rev Bras Ortop. 2010;45(2):116-21.

4. Volpon JB, Carvalho Filho G. Luxação congênita do quadril no recém-nascido. Rev Bras Ortop. 1985;20(7):317-20

5. Bowen JR, Kotzias-Neto A. Developmental dysplasia of the hip. Brooklandville: Data Trace Publishing Company; 2006.

6. Dega W. Selection of surgical methods in the treatment of congenital dislocation of the hip in children. Chir Narzadow Ruchu Ortop Pol.1969;34(3):357-66.

7. Mubarak SJ, Valencia FG, Wenger DR. One-stage correction of the spastic dislocated hip. Use of pericapsular acetabuloplasty to improve coverage. J Bone Joint Surg Am. 1992;74(9):1347-57.

8. Wiberg G. Studies on dysplastic acetabula and congenital sublux- ation of the hip joint. With special reference to the complication of osteoarthritis. Acta Chir Scand. 1939;58-83(Suppl):5-135.

9. Jones DH. Shenton's line. J Bone Joint Surg Br. 2010;92(9):1312-5.

10. Salter RB, Kostuik J, Dallas S. Avascular necrosis of the femoral head as a complication of treatment for congenital dislocation of the hip in Young children: a clinical and experimental investigation. Can J Surg. 1969;12(1):44-61.

11. Al-Ghamdi A, Rendon JS, Al-Faya F, Saran N, Benaroch T, Hamdy RC. Dega osteotomy for the correction of acetabular dysplasia of the hip: a radiographic review of 21 cases. J Pediatr Orthop. 2012;32(2):113-20.

12. Tönnis D. Normal values of the hip joint for the evaluation of X-rays in children and adults. Clin Orthop Relat Res. 1976;(119):39-47.

13. Cooperman DR, Wallensten R, Stulberg SD. Acetabular dysplasia in the adult. Clin Orthop Relat Res. 1983;(175):79-85.

14. El-Sayed MM, Hegazy M, Abdelatif NM, EIGebeily MA, EISobky T, Nader S. Dega osteotomy for the management of developmental dysplasia of the hip in children aged 2-8 years: results of 58 consecutive osteotomies after 1325 years of follow-up. J Child Orthop. 2015;9(3):191-8 
In the article entitled "MODIFIED DEGA OSTEOTOMY IN TREATING DEVELOPMENTAL DYSPLASIA OF THE HIP" authored by Roberto Guarniero, Fernando Barbosa Sanchez, Bruno Sergio Ferreira Massa, Nei Botter Montenegro, Patrícia Moreno Grangeiro, Luiz Renato Agrizzi De Angeli, published in Revista Acta Ortopédica Brasileira (ACTA) vol.26 n 1, 2018 , page 30, DOI: http://dx.doi.org/10.1590/1413-785220182601181195, by request of the authors.

Where it reads: Roberto Guarnieiro

Read: Roberto Guarniero 